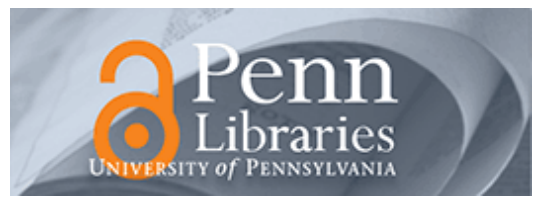

University of Pennsylvania

ScholarlyCommons

Management Papers

Wharton Faculty Research

$5-1994$

\title{
A Laboratory Investigation of Multiperson Rationality and Presentation Effects
}

Andrew Schotter

Keith W. Weigelt

University of Pennsylvania

Charles Wilson

Follow this and additional works at: https://repository.upenn.edu/mgmt_papers

Part of the Behavioral Economics Commons, Management Information Systems Commons, Management Sciences and Quantitative Methods Commons, and the Organizational Behavior and Theory Commons

\section{Recommended Citation}

Schotter, A., Weigelt, K. W., \& Wilson, C. (1994). A Laboratory Investigation of Multiperson Rationality and Presentation Effects. Games and Economic Behavior, 6 (3), 445-468. http://dx.doi.org/10.1006/ game.1994.1026

This paper is posted at ScholarlyCommons. https://repository.upenn.edu/mgmt_papers/164

For more information, please contact repository@pobox.upenn.edu. 


\title{
A Laboratory Investigation of Multiperson Rationality and Presentation Effects
}

\author{
Abstract \\ This paper reports the results of laboratory experiments in which subjects were presented with different \\ two-person decision problems in both their extensive and normal forms. All games generated the same \\ equilibrium outcomes. Our results indicate that the presentation of the decision problem significantly \\ affects the strategy chosen. Surprisingly, these presentation effects were most prominent in the simplest \\ games where differences in presentation would seem most transparent. It appears that subjects are \\ much more likely to use (and fear) incredible threats when the problem is presented as a one-stage rather \\ than as a multistage game.

\section{Disciplines} \\ Behavioral Economics | Management Information Systems | Management Sciences and Quantitative \\ Methods | Organizational Behavior and Theory
}


A Laboratory Investigation of Hulti-Person

Rationality and Presentation Effects

\author{
by \\ Andrew Schotter \\ New York University \\ 269 Mercer Street \\ New York, NY 10003 \\ 212-998-8909 \\ Keith Weigelt \\ Department of Management \\ University of Pennsylvania \\ The Wharton School \\ Philadelphia, PA 19104 \\ $215-898-6369$ \\ Charles Wilson \\ Department of Economics \\ New York University \\ 269 Mercer Street \\ New York, NY 10003 \\ 212-998-8954 \\ June 7, 1990
}

We thank the C.V. Starr Center for Applied Economics for financial support. Thanks also to participants of the Strategy Workshop at The Wharton School, Colin Camerer, and George Mailath for helpful comments. 
ABSTRACT

This paper reports the results of a series of laboratory experiments in which different groups of subjects were presented with a series of 2-person decision problems all of which generate the same equilibrium outcomes. Each problem was presented to different groups of subjects in at least two ways. In some cases, it was explicitly represented as a multistage game while in others it was represented as a one stage game in which both subjects choose their strategies simultaneously. Although the games varied in their complexity, in no case did a subject have more than three strategies from which to choose, and, in each case, one of the players could guarantee a secure outcome while the other player possessed a self-defeating (incredible) threat.

In some cases, the form in which the decision problem is presented significantly affects the outcome. Surprisingly, these effects were most prominant in the simplest decision problems where the differences in presentation would seem to be most transparent. In these simple problems, it appears that subjects are much more likely to use (and fear) incredible threats when the problem is presented as a one-stage rather than a multistage game. 


\section{Introduction}

Kohlberg and Mertens (1986) have identified a number of properties which they believe should be satisfied by any solution concept in games in which it is common knowledge that all players are perfectly rational. Among others, they argue that the choices of the players should be undominated, survive the iterated deletion of dominated strategies, and satisfy various solution concepts based on backwards induction. In addition, they also insist that rational decision making implies that the solution of any game should be invariant to the extensive form representation. ${ }^{1}$ In contrast, some experimental studies of individual decision making under uncertainty (see, for example Kahneman and Tversky (1979)) indicate that the behavior of real human beings may depend, sometimes dramatically, on how a problem is presented to the subjects.

Our objective in this paper is twofold. First, we investigate the circumstances under which two of the principles of rationality mentioned above, backward induction and iterated dominance, are likely to govern the behavior of subjects in actual decision problems. Second, we investigate the extent to which the "frame" or form of presentation of the game affects the way subjects play it. These two objectives are related since the form in which a decision problem is presented to subjects may make one of the rationality principles stated above more salient. For example, while iterated dominance can be defined in the normal of a game, subgame perfection cannot. In contrast, iterated dominance may be less transparent for games presented in an extensive form with a sequence of moves.

\footnotetext{
1 This is in contrast to refinements based on the extensive form of a game, such as perfection (Selten (1975)) and sequential rationality (Kreps and Wilson (1981)).
} 
We performed a series of experiments in which different groups of subjects were presented with various two person games all of which generate the same equilibrium outcomes. The games were related in two ways. First, each had a similar sequential structure and each had the same set of Nash equilibrium payoffs. They differed in the set of subgame perfect outcomes or in the set of outcomes which survived the deletion of dominated strategies (by pure strategies). Second, each game was presented in two different forms. To some groups of subjects the game was presented and described in the normal form as a matrix of strategies and payoffs. To other groups of subjects the game was presented and described in an extensive form with an explicit sequential structure. In no case did a subject have more than three strategies from which to choose. In each case, one of the players could guarantee a secure outcome and the other player possessed a self-defeating (incredible) threat.

Our results strongly confirm the presence of significant framing or presentation effects. In a simple two stage game with just two strategies for each player, we observed a dramatic difference in the behavior of the subjects depending on whether the game was presented as matrix in which the players move simultaneously or as a tree in which the players move sequentially. However, we were unable to substantiate the impact that the presentation of a problem has on the saliency of our two principles of rationality. In those experiments where we expected that our rationality principles would predict differences in behavior across game forms, either no such differences appeared or the differences were not what we expected.

The paper is organized as follows. Section 2 presents the decision problems which form the basis of our experiment. Section 3 describes our 
experimental design and reviews our experimental procedures. In Section 4 we formulate three hypotheses around which we organize the discussion of the results of experiments in Section 5. In Section 6 we discuss some issues arising from the analysis of our results and present the results of some additional experiments. In Section 7, we discuss some related experimental work by other researchers. Section 8 summarizes our conclusions.

\section{Presentation Effects and Rationality}

We designed a set of six complementary two-person decision problems. These decision problems are described below.

\subsection{The Baseline Problem: Backward Induction and Iterated Dominance}

Problems 1M and 1S below constitute our baseline problems. They are strategically equivalent in the sense that their set of strategies and payoffs are isomorphic. Subject A has two strategies. If he chooses "L", both subjects receive a payoff of 4 . If he chooses " $R$ ", the payoff depends on the strategy chosen by subject B. If subject B chooses " $L$ ", subject A earns 0 and subject B earns 1 . If he chooses "R", subject A earns 6 and subject $B$ earns 3 .

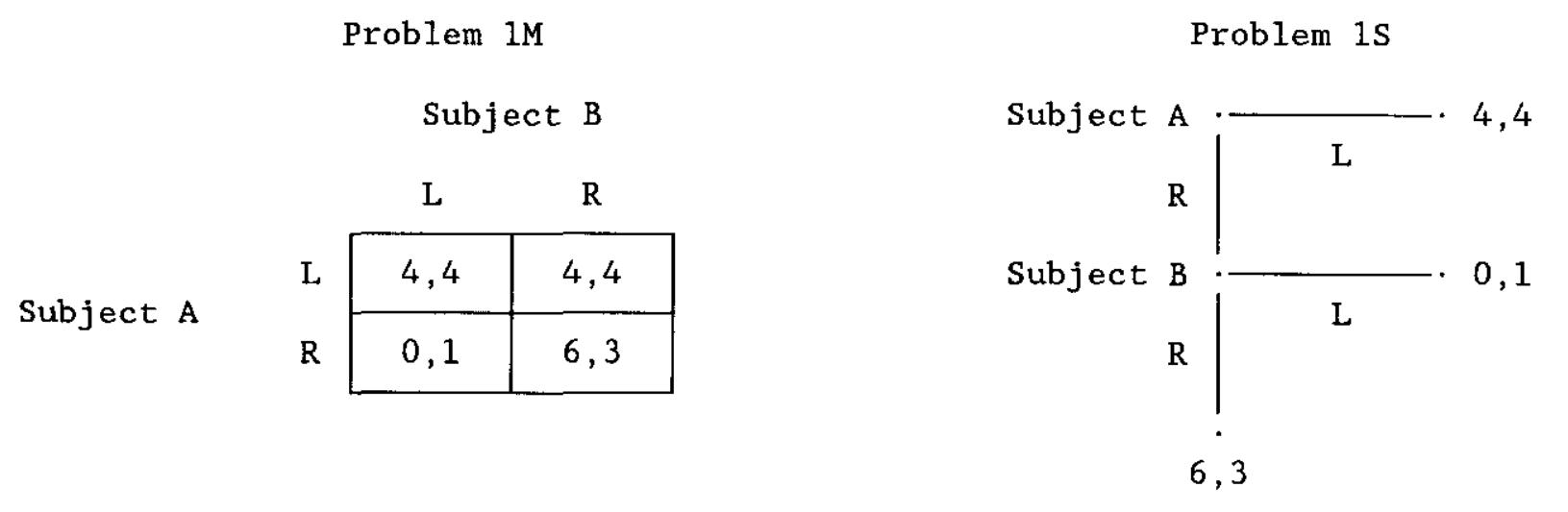


There are two Nash equilibrium outcomes, $(4,4)$ and $(6,3)$. However, $(6,3)$ is the only outcome which survives the deletion of dominated strategies, and, in problem 1S, it is the only subgame perfect outcome. Thus, both of the principles of rationality mentioned above lead to the same outcome.

The next two pairs of games are variations on the baseline problem.

They are designed to isolate the role of iterated dominance and backward induction as the effective principles which guide the behavior of the subjects.

\subsection{Backward Induction Without Iterated Dominance}

Problems $2 \mathrm{M}$ and $2 \mathrm{~S}$ below are strategically equivalent games with the same set of equilibrium payoffs as the baseline problem. They differ from the baseline problem only in that the $(6,3)$ outcome has been replaced with a subgame with the same (mixed strategy) equilibrium payoff. In problem (2S), the natural extensive form of the game, subgame perfection again requires both players to choose " $R$ " to obtain an expected outcome of $(6,3)$.

However, both the $(4,4)$ and $(6,3)$ outcomes survive the deletion of dominated strategies (with respect to pure strategies ${ }^{2}$ ).

2 The $(4,4)$ outcome does not satisfy the deletion of strategies dominated by mixtures of strategies. For instance a convex combination of $M$ and $B$ dominates $T$ for player $b$. To construct a game in which $(4,4)$ survives iterated dominance by mixed strategies requires at least four strategies for each player with a complicated set of payoffs. We did not study such a game because we did not want to introduce such complexity into the subgame. Nevertheless, the current design is certainly flawed as a test of subgame perfection in the absence of iterated dominance. 
Problem 2M

Subject $B$

\begin{tabular}{cc|c|c|c|}
\multicolumn{1}{c}{} & \multicolumn{2}{c}{$\mathrm{T}$} & \multicolumn{1}{c}{$\mathrm{M}$} & \multicolumn{1}{c}{$\mathrm{B}$} \\
\cline { 3 - 5 } Subject & $\mathrm{T}$ & 4,4 & 4,4 & 4,4 \\
\cline { 3 - 5 } A & M & 0,1 & 7,0 & 5,6 \\
\cline { 3 - 5 } & B & 0,1 & 5,6 & 7,0 \\
\cline { 3 - 5 } & & &
\end{tabular}

Problem 2S

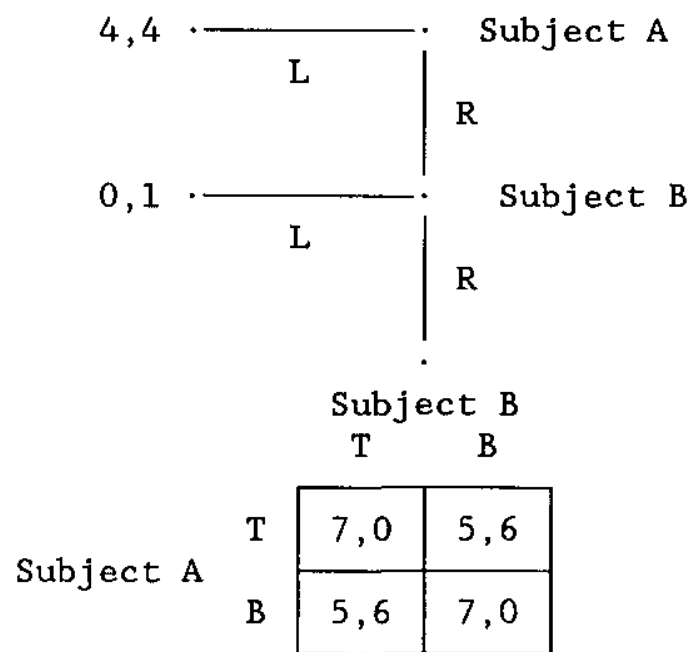

\subsection{Iterated Dominance Without Backward Induction}

Problems $3 \mathrm{M}$ and $3 \mathrm{~S}$ represent another pair of strategically equivalent variations on the baseline problem. Again the $(6,3)$ payoff has been replaced with a simple bimatrix game. In this case, however, the subgame has two equilibria $(6,3)$ and $(3,6)$. Consequently, both $(4,4)$ and $(6,3)$ are subgame perfect. However, since " $\mathrm{T}$ " dominates "B" for player $\mathrm{A}$ in problem 3M (equivalently, "L" dominates "TB" in problem 3S), it follows that only the $(6,3)$ outcome survives iterated deletion of (weakly) dominated strategies. 
Problem 3M

Subject B

\begin{tabular}{cc|c|c|c|}
\multicolumn{1}{c}{} & \multicolumn{1}{c}{$\mathrm{T}$} & \multicolumn{1}{c}{$\mathrm{M}$} & \multicolumn{1}{c}{$\mathrm{B}$} \\
\cline { 3 - 5 } Subject & $\mathrm{T}$ & 4,4 & 4,4 & 4,4 \\
\cline { 3 - 5 } A & M & 0,1 & 6,3 & 0,0 \\
\cline { 3 - 5 } & B & 0,1 & 0,0 & 3,6 \\
\cline { 3 - 5 } & & &
\end{tabular}

Problem 3S

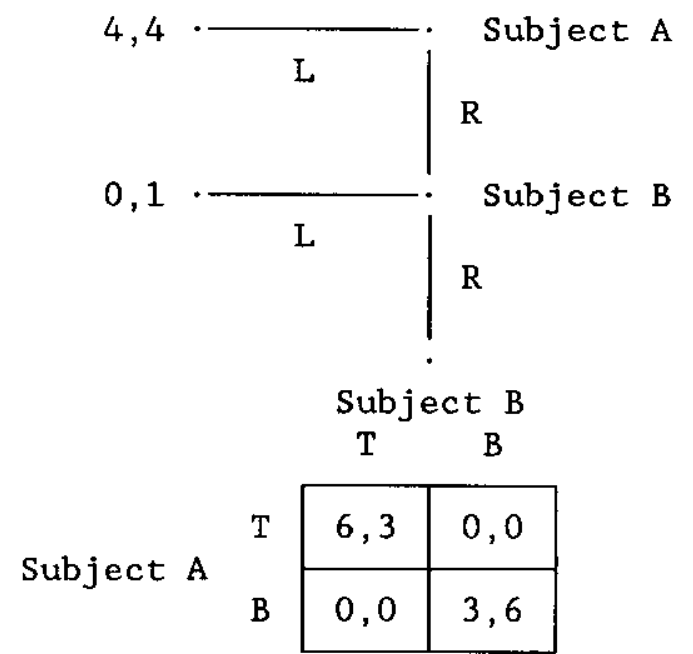

\subsection{A Summary of the Outcomes}

Table 3.1 summarizes the outcomes of the different games in relation to the hypotheses which we formulate in Section 5 below. In each case, both the matrix and sequential versions of the game have the same pair of Nash equilibrium outcomes. In the matrix version of the games, subgame perfection adds no restrictions. However, in the sequential versions, it restricts the outcome to $(6,3)$ in games $1 \mathrm{~S}$ and $2 \mathrm{~S}$, but leaves both the $(4,4)$ and $(6,3)$ outcome in game $3 \mathrm{~S}$. In Section 5, we suggest that iterated dominance may be more transparent in the matrix version of the games. Restricting attention to the matrix versions of the games, the deletion of strategies weakly dominated by pure strategies results in the $(6,3)$ outcome in games $1 M$ and $2 M$, but leaves both the $(4,4)$ and $(6,3)$ outcomes in game $2 \mathrm{M}$. 
TABLE 3.1 Summary of Decision Problems

\begin{tabular}{|c|c|c|c|c|}
\hline Exper. & Structure & NE & $\begin{array}{l}\text { - Outcomes } \\
\text { Iter. Dom. }\end{array}$ & 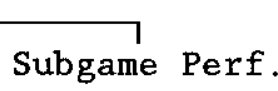 \\
\hline $1 \mathrm{M}$ & Matrix & $(6,3),(4,4)$ & $(6,3)$ & $\ldots$ \\
\hline $1 \mathrm{~S}$ & Sequential & $(6,3),(4,4)$ & $\cdots$ & $(6,3)$ \\
\hline $2 \mathrm{M}$ & Matrix & $(6,3),(4,4)$ & $(6,3),(4,4)$ & $\ldots$ \\
\hline $2 \mathrm{~S}$ & Sequential & $(6,3),(4,4)$ & $\ldots$ & $(6,3)$ \\
\hline $3 \mathrm{M}$ & Matrix & $(6,3),(4,4)$ & $(6,3)$ & $\ldots$ \\
\hline $3 \mathrm{~s}$ & Sequential & $(6,3),(4,4)$ & 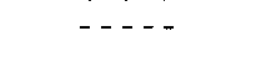 & $(6,3),(4,4)$ \\
\hline
\end{tabular}

\section{Experimental Design}

The instructions for problems $1 M$ and $1 S$ are included in Appendix $A$. (The instructions for the other problems is available on request.) Subjects were New York University undergraduate students, drawn primarily from first year economics courses. Each subject participated in only one decision problem.

Typically, there were a total of ten subjects in any given experimental session. Each subject sat at a PC terminal and was given a copy of the instructions. Half of the subjects were randomly assigned to be type A and half assigned to be type B. Each subject was informed of only his own type. The experiment administrator read the instructions aloud and publicly answered any questions. Subjects then played six practice rounds with a partner chosen at random in each round. To avoid biasing the choices in the actual experiment to follow, letters rather than numbers were used to stand for payoffs during the practice rounds. Upon completion of the practice rounds, the subjects were randomly assigned a different partner in each of the successive rounds. Consequently, the number of rounds played by any group of 
subjects depended on the number of subjects in the group. The subjects were explicitly told that no two subjects were ever paired against each other more than once.

After both a subject and his partner made their choices, the choice of the subject and his payoff were listed on the screen along with his choices and payoffs in any previous rounds. (In the practice rounds the payoff letter was used.) Subjects were not explicitly informed of the action taken by their partners. This guaranteed that a subject obtained the same information about the behavior of his partner in all versions of the problem. The subjects were told that each payoff point they earned could be cashed in for $\$ .70$. Typical earnings ranged from $\$ 12$ to $\$ 18$.

In designing the experiment, we had two major concerns. Our biggest concern was that the subjects perceive the problem as a one shot game and not try to establish a norm for future play through their own actions. In a pilot experiment we let the subjects play against opponents selected at random for 30 rounds with much lower payoffs in each round. In a post experiment questionnaire, a significant proportion of the subjects indicated that they were trying to build a reputation across rounds, even though there was only a small probability that they would face another subject more than once. After the design change, responses to a similar questionnaire indicated that these kind of considerations were not a significant factor.

\section{Hypotheses}

Our experimental design allows us to conduct a number of tests relating the presentation of a game to the way it is played. First of all there is a simple test of the "invariance" principle which requires that the 
solution of a game be invariant with respect to its representation. Second, if the solution proves not be invariant, then we may investigate the relation between the saliency of specific "principles of rationality" and the form in which a game is represented or described to the players.

\subsection{Invariance}

Kohlberg and Mertens (1986) argue that the set of outcomes of a game which constitute a self-enforcing agreement should depend only on its strategic form. Consequently, if the solution is unique, it should predict the same behavior regardless of how the game is represented. A weaker hypothesis, but one which does not presume the validity of any particular solution concept is simply to predict that the actual play of the game is independent of its representation. This leads to the following null hypothesis.

Hypothesis I (invariance): In each pair of games, the outcomes should occur in the same proportion in the two representations.

In fact, if we assume that the agents act independently, the actions of each subject type should occur in the same proportion. The independence assumption is required because when subject $A$ chooses " $L$ " in the sequential version of a game, subject B is not given an opportunity to respond. Consequently, in the sequential version of a game, we observe only the action of subject B when player A chooses "R", while we always observe his action in the matrix version. 


\subsection{The Saliency of Subgame Perfection and Iterated Dominance}

In opposition to the invariance principle, there is considerable evidence by researchers such as Kahneman and Tversky (1979) that the presentation or "frame" of a problem may substantially influence the decisions of subjects. Similarly, in the context of a multiperson decision problem, its presentation may influence the confidence with which the participants believe it is common knowledge that all participants respect a given rationality principle. We wished to test two conjectures. First, we conjectured that backward induction is more salient when the sequential nature of the game is emphasized. Second, we conjectured that solutions consistent with the iterated deletion of dominated strategies are more likely when the game is represented in strategic form so that the dominance relations are more apparent. Our remaining hypotheses were designed to operationalize these conjectures.

Since Problem 2 contains no strategies which are dominated by pure strategies, but does contain a unique subgame perfect equilibrium in the sequential version of the game, our first conjecture suggests the following hypothesis:

Hypothesis II (backward induction): The proportion of times in which subjects play in a way which is consistent with an expected return of $(6,3)$ when playing game $2 \mathrm{~S}$ is no less than when playing game $2 \mathrm{M}$.

Similarly, in Problem 3 , both the $(4,4)$ outcome and the $(6,3)$ outcome are subgame perfect in both versions of the game, while only the $(6,3)$ outcome survives the iterated deletion of dominated strategies. Since we conjectured 
that the subjects are more likely to believe that both players are aware of the dominance relations when the game is represented as a matrix, we were led to the following hypothesis.

Hypothesis III (iterated dominance): The proportion of times in which subjects achieve the $(6,3)$ outcome when playing game $3 M$ is no less than when playing game $3 \mathrm{~S}$.

\section{The Results}

In this section, we summarize the results of our basic experiments and discuss the implications for the three hypotheses stated above. The results are tabulated in Tables 1 to 4. For all of the basic experiments, we report the number of responses of each choice in each round aggregated across cohorts. We also present the total number of responses of each choice by cohort. To check for differences across individuals, we also report the number of subjects who made each choice a given number of times in the matrix version of the games. (This information for the sequential games is less informative since the number of choices a given subject makes is variable.)

A complete history of each subject is available from the authors upon request. Given the preliminary nature of the investigation, we have not performed any formal statistical tests.

\section{$5.1 \quad$ Hypothesis I}

Table 1 summarizes the results for the baseline experiment, Problem 1. A total of 20 subjects of each type played at least three rounds of the matrix version $1 M$ and 16 subjects played at least five rounds of the sequential 
version 1S. For game 1M, 578 of the type A responses were to play the secure strategy "L" and $20 \%$ of the type B responses were to play the dominated strategy "L". For game $1 \mathrm{~S}$, both types of subjects almost always chose " $R$ ". (Of the seven "L" responses by type A subjects, six were by the same subject who later indicated that he had misunderstood the payoffs.)

The results suggest a clear rejection of the invariance hypothesis I. The presentation of the game appears to have significantly affected the way both types of players play the game.

\subsection{Hypothesis II}

Table 2 summarizes the results for Problem 2. Ten subjects of each type played 5 rounds of both the matrix and sequential versions. In the matrix version $2 \mathrm{M}, 288$ of the type A responses were to play the secure choice "T", while $12 \%$ of the type $B$ responses were to employ the threat "T". For game 2S, 248 of the type A responses were to play the secure choice "L", while 108 of the type B responses were to employ the threat strategy "L".

Since there appears to be no significant difference in the way subjects play the two versions, we cannot reject hypothesis II. On the other hand, our results do not give any positive evidence that the subgame perfection in the absence of clear iterated dominance is particularly salient as solution principle.

The results of Problem 2 were surprising in two respects. First, the strong presentation effect which we observed in Problem I completely disappeared, even though the problems are quite similar. Second, the behavior of subjects in the matrix version of the game is not what we would have expected given their behavior in the corresponding version of Problem 1 . Type 
A subjects were more likely to play the secure strategy and type B subjects as least as 1ikely to play the threat strategy in game $1 M$ as in game $2 M$ even though the dominance of the threat strategy is much clearer in Problem I.

\subsection{Hypothesis III}

Table 3 summarizes the results for Problem 3 . Ten subjects of each type played 5 rounds of the matrix version of the game and ten subjects of each type played 5 rounds of the sequential version. The unique iterated dominance equilibrium outcome $(6,3)$ was attained only two times in the matrix version $3 M$ and 4 times in the sequential version $3 S$. The low number of hits reflects the fact that the secure choice "T" was chosen by type A subjects 828 of the time in matrix version $3 M$ and $70 \%$ of the time in the sequential version $3 \mathrm{~S}$.

Beyond the fact that the iterated dominance solution was rarely chosen in either version, the behavior of the subjects indicates additional support for the hypothesis that iterated dominance is no less likely to be salient when the game is presented as a simultaneous move game. In neither case, did the type A subjects play the dominated strategy (" $B$ " in game $3 M$ and " $R B$ " in game 3S) more than twice. However, once these dominated strategies are eliminated, player B strategies "B" (in 3M) and "RB" (in 3S) are weakly dominated by "M" and "RT" respectively. Yet type B players played "M" 13 times and "B" only 2 times in the matrix version, while in the sequential version, they played the analogs "RT" 4 times and "RB" 9 times. It appears, therefore, that type B players are less likely to play the strategies which are weakly dominated after the deletion of the dominated type A strategies in the matrix version of the game. (In a later test, reported in Section 6.4 below, however, we observed quite different behavior.) 


\section{Nev Questions and Further Tests}

Although our results suggest some clear patterns they have raised more questions than they have answered. In this section we explore some of these new questions and indicate some preliminary attempts to address some of them.

\subsection{Framing in Description versus Framing in Structure}

In both problems 1 and 3 , the threat strategy is used much less frequently in the matrix versions of the game than in the sequential version, (In problem 2, there is no appreciable difference.) In both cases, the threat strategy is dominated (by a mixed strategy in game 3). Various factors might account for these differences. However, it may be worth noting that in the matrix version, the dominance is weak, while in the sequential version, the dominance is strong at the start of the subgame at which subject B makes his choice. One might argue, therefore, that we are testing for more than just a presentation effect. We are also testing whether their responses are affected by a change in the description of the game combined with a corresponding change in the information available to the subjects at the time the make their decisions .

To separate these two effects, we constructed a hybrid version of Problem I in which the game was described sequentially and represented as a tree as in experiment $1 \mathrm{~S}$, but in which player $B$ was required to make his choice simultaneously with player A as in experiment $1 \mathrm{M}$. That is, subject $B$ was required to commit himself to a course of action in the event that subject A chose " $R$ " before being told whether or not he would actually be given a choice. 
The results are reported in Table 4. Fifteen subjects of both types participated in the experiment in at least four rounds each. Fourteen percent of the type A responses were to play the secure strategy "L". Twelve percent of the type $B$ responses were to play the dominated threat strategy "L". The number of observations is probably too limited to be conclusive. However, the results suggest that both the change in description of the game and its structure influence the play of the subjects. Both types of subjects are more likely to play in a way consistent with $(6,3)$ outcome in the hybrid version than in the matrix version, but they are less likely to reach the $(6,3)$ outcome in the hybrid version than in the sequential version.

\subsection{Modifications of Problem 3}

In Problem 3S, type B subjects were given an opportunity to respond only 308 of the time. Evidently the risk of not coordinating in the second period was sufficiently great to deter a choice of " $R$ ". To induce type $A$ subjects to choose " $R$ " more often, we also ran a few sessions in which the payoffs in the second stage of the game were modified. In one case, we replaced off diagonal payoffs of $(0,0)$ with $(2,2)$. In another case, we replaced the $(6,3)$ and $(3,6)$ payoffs with $((8,4)$ and $(4,8)$. Both matrix and sequential versions of these games were tested. The results are reported in Tables 6 and 7 .

The results do not suggest any major revisions in our conclusions. As might be expected, type A subjects played the secure strategy less often. Also, type B subjects played strategy "B" more often. Player B also played the threat strategy less often, although not as infrequently as might be expected. In the matrix version with $(2,2)$ payoffs on the off diagonals, his 
threat strategy "T" is strongly dominated. Yet type B subjects played "T" $11 \%$ of the time. This behavior may be limited to a small fraction of the population, however. Only 3 of the 12 subjects ever chose this response and one of the subjects chose it 4 times.

\subsection{Communication and Learning}

In each of the games, the solution implied by one or both of the rationality principles defined above is unique. However, this outcome is consistently attained in only problem 1S. In all of the other cases, the observed behavior is not consistent with any Nash equilibrium. Furthermore, most of the subjects experimented with different choices in the three to six rounds they played the game. This suggests that the subjects were not very confident about how their opponents would play the game.

A common interpretation of Nash equilibrium and its various refinements is that it is a self enforcing convention (or at least that any self enforcing convention is contained in the set of Nash equilibria). Therefore, the test of the refinement (or its underlying principles) should not be based only on how agents play the game in the first few rounds or even after several rounds. Rather, it should satisfy the following two criteria. First, no convention which is not consistent with that refinement can be sustained. Second, we should be able to demonstrate that there is a method of leading the subjects to consistently play according to a convention which does satisfy that refinement. This suggests that we need to redesign the experiment to give subjects more opportunities to establish a convention. We mention here three possible methods of testing to see which if any conventions of play can be adopted and sustained. One is to allow the players 
to play more rounds of the game, alternating roles, with more time to contemplate their actions between rounds. For instance, they might be asked to explicitly predict the action of their opponent before making their choice as in Van Huyck, Battaliio, and Beil (1990). Another possibility is to allow for preplay communication which gives agents an opportunity to explain their reasoning and to explicitly agree on a convention. (See Cooper, De Jong, Forsythe, and Ross for a nice study of the effect of preplay communication in the battle of the sexes game.) Finally, we might publicly suggest various convention of play, perhaps with some accompanying explanation, and determine which conventions are sustained. This approach has been used by Van Huyck, Gillette, and Battalio (1989) to test various deductive equilibrium selection principles .

To date we have experimented only with the possibility of reversing roles and only in problem 3M. In one session, we informed the subjects that they were to participate in two experiments. At the end of the first experiment they were given the same game but assigned the opposite role. The results are reported in Table 8 . For the first six rounds of the experiment, most type A responses were the secure strategy "T", while most type B choices were strategy "B". In the second six rounds, with the roles of the subjects reversed, the behavior of the new type A subjects was largely the same as before. If anything, there was an even greater tendency to play the secure strategy. However, there does appear to have been a significant change in the behavior of the type B subjects (formerly type A subjects). During these rounds, type B subjects chose strategy "M" slightly more often than "B". There was less variation in the responses of individual subjects after the roles were reversed, suggesting that the individual subjects were more 
convinced of their best responses. However, it is not clear what convention, if any, the subjects would eventually settle upon if the process were continued. We suspect the change in behavior the behavior of the type $B$ subjects is indicative of a tendency which would persist if even more rounds were played. We also suspect that the change in behavior after the roles were reversed was due in part to the fact that the subjects had a chance to think about the game while the procedures were explained again and the monitor checked to make sure everyone understood their roles in the remaining rounds.

\section{Related Work}

Although we are not aware of any work which focuses on explicitly on the presentation effects which we study here, several authors have begun to investigate the saliency of various solution concepts in games involving a small number of players. Future work on studying presentation effects should benefit both from the insights these studies yield as well as their methodology.

We may divide this work into two groups. The first body of work is concerned with testing various principles of equilibrium selection. Roughly speaking, a selection principle is designed to complement a theory of multiperson rationality when that theory does not lead to a unique prediction of behavior. Examples of selection principles are symmetry, payoff dominance, and payoff security. Several authors have recently begun to investigate the saliency of these various criteria and their dependence on the structure of the game. Particularly noteworthy is the work of Cooper, DeJong, Forsythe, and Ross (1990) and the work of Van Hyuck, Battalio, and Beil (1990) and Van Huyck, Gillette, and Battalio (1989). Typically, they consider coordination 
games in which there are several equilibria satisfying even the strongest refinements but in which various selection principles give different but unique solutions. Their work provides convincing evidence that no single selection principle is always salient. Although we are concerned with testing how the presentation of a game affects the saliency of different principles of refinement, the general approach is quite similar. In both cases, the basic question is not if a principle is salient, but when the principle is salient. The other line of experimental work is on equilibrium refinements. Much of it has focused on the explanatory power of backward induction in multistage games. There are several questions yet to be settled in this literature, particularly with respect to the role of learning. Nevertheless, it does appear that there are severe limitations to the saliency of backward induction in games with many stages or in games in which issues of fairness arise. Our results suggest that merely the presentation (or the interpretation) of the problem may also have a significant effect.

Several investigators have also begun to study the explanatory power of various forward induction refinements in the context of games of incomplete information. Camerer and Weigelt (1988) test a multistage reputation game and find that the behavior of the subjects is better explained by the "intuitive" criterion (Cho and Kreps (1987) than any other sequential equilibrium. Similarly, Brandts and Holt (1987) test a version of the Cho-Kreps "beer-quiche" game with two sequential equilibria. They also find that the behavior of subjects is better explained by the unique equilibrium satisfying the intuitive criterion. Banks, Camerer, and Porter (1988) investigate a broad class of games to try to determine the appropriate forward induction criteria. They conclude that generally the concept of "divinity" (Banks and 
Sobel (1987)) accords best with the data. Problem 3 above is most closely related to this work.

Finally, we should mention the work of Beard and Bell (1990) which investigates the confidence with which players have in the rationality of others. They consider a set of games similar to 15 , except that the secure payoff to player A is generally much closer to the subgame perfect payoff and the threat strategy of player $B$ is not necessarily lower from his payoff when player A plays the secure strategy. In contrast to our results, they find that a significant fraction (sometimes over 50\%) of the type A players choose the secure strategy. Our results suggest that if the subjects were to play the matrix version of the game, almost none of the subjects would play the secure strategy.

\section{Summary and Conclusion}

The behavior of the subjects in problem I strongly rejects the hypothesis that the behavior of subjects is invariant to the form of presentation of the game. Problem I is a simple two stage game with a secure strategy for one player and an incredible threat for the other. Yet the outcome of the game is typically quite different when the game is described and played as a static problem rather than as a sequential problem.

Problem II, which was designed to isolate the explanatory power of subgame perfection, is probably flawed. First, the subgame perfect outcome requires mixed strategies which introduces an additional degree of complication and requires stronger assumptions about the preferences of the subjects. Second, once we consider mixed strategies, the $(4,4)$ outcome is again eliminated by the iterated deletion of weakly dominated strategies. 
Although subgame perfection is distinct from iterated dominance, the two concepts are very closely related when the information structure is relatively simple. It is probably more useful to establish less subtle properties before trying to firmly establish whether which of the two principles is more salient.

In neither the matrix nor the sequential version did we generally obtain the forward induction solution of Problem 3. Evidently it requires more experience in the game for players to confidently predict the rational responses of their opponents than permitted by our experimental design. Finally, we did accumulate some evidence that subjects are much less likely to play a strongly dominated strategy than a weakly dominated strategy. 
Table 1: Aggregated Results for Problem 1

Matrix Version IM

B

A

L

\begin{tabular}{|l|l|}
\hline 4,4 & 4,4 \\
\hline 0,1 & 6,3 \\
\hline
\end{tabular}

Sequential Version is

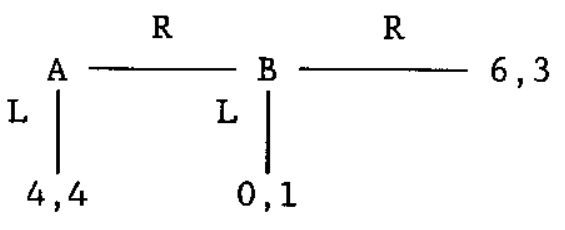

Number of Subjects Making Each Choice

Game:

$1 \mathrm{M}$

1S

\begin{tabular}{|c|c|c|c|c|c|c|c|c|}
\hline \multirow{2}{*}{$\begin{array}{l}\text { Subject: } \\
\text { Choice: }\end{array}$} & \multicolumn{2}{|c|}{ A } & \multicolumn{2}{|c|}{ B } & \multicolumn{2}{|c|}{ A } & \multicolumn{2}{|c|}{ B } \\
\hline & L & $\mathrm{R}$ & L & $\mathbf{R}$ & L & $\mathrm{R}$ & $\mathrm{L}$ & $\mathrm{R}$ \\
\hline Total & 46 & 34 & 16 & 64 & 7 & 79 & 2 & 77 \\
\hline \multicolumn{9}{|l|}{ Round } \\
\hline 1 & 12 & 8 & 6 & 14 & 2 & 14 & 0 & 14 \\
\hline 2 & 11 & 9 & 4 & 16 & 1 & 15 & 1 & 14 \\
\hline 3 & 11 & 9 & 2 & 18 & 1 & 15 & 0 & 15 \\
\hline 4 & 9 & 5 & 3 & 11 & 1 & 15 & 1 & 14 \\
\hline 5 & 3 & 3 & 1 & 5 & 1 & 15 & 0 & 15 \\
\hline 6 & 0 & 0 & 0 & 0 & 1 & 5 & 0 & 5 \\
\hline \multicolumn{9}{|l|}{ Cohort } \\
\hline 1 & 16 & 14 & 7 & 23 & 1 & 24 & 0 & 24 \\
\hline 2 & 3 & 6 & 0 & 9 & 0 & 25 & 1 & 24 \\
\hline 3 & 9 & 7 & 5 & 11 & 6 & 30 & 1 & 29 \\
\hline 4 & 12 & 4 & 2 & 14 & & & & \\
\hline 5 & 6 & 3 & 2 & 7 & & & & \\
\hline
\end{tabular}


Table 2: Aggregated Results for Problem 2

Matrix Version 2M

\begin{tabular}{|c|c|c|c|}
\hline & \multicolumn{3}{|c|}{ B } \\
\hline & $\mathrm{T}$ & M & B \\
\hline $\mathrm{T}$ & 4,4 & 4,4 & 4,4 \\
\hline A & 0,1 & 7,0 & 5,6 \\
\hline B & 0,1 & 5,6 & 7,0 \\
\hline
\end{tabular}

Sequential Version 2S

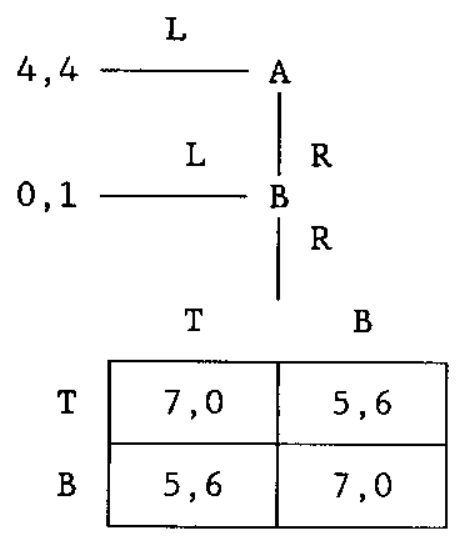

Number of Subjects Making Each Choice

$\begin{array}{lll}\text { Game: } & 2 \mathrm{M} & 2 \mathrm{~S}\end{array}$

\begin{tabular}{|c|c|c|c|c|c|c|c|c|c|c|c|c|c|}
\hline \multirow{2}{*}{$\begin{array}{l}\text { Subject: } \\
\text { Choices: }\end{array}$} & \multicolumn{3}{|c|}{ A } & \multicolumn{4}{|c|}{ B } & \multicolumn{3}{|c|}{ A } & \multicolumn{3}{|c|}{ B } \\
\hline & $\mathrm{T}$ & M & B & $\mathrm{T}$ & M & B & $\mathrm{L}$ & $\mathrm{R}$ & RT & $\mathrm{RB}$ & L & RT & $\mathrm{RB}$ \\
\hline Total & 14 & 19 & 17 & 6 & 14 & 30 & 12 & 38 & 24 & 10 & 4 & 10 & 24 \\
\hline Round & & & & & & & & & & & & & \\
\hline 1 & 4 & 3 & 3 & 3 & 1 & 6 & 5 & 5 & 4 & 0 & 1 & 2 & 2 \\
\hline 2 & 5 & 2 & 3 & 0 & 4 & 6 & 2 & 8 & 7 & 1 & 0 & 4 & 4 \\
\hline 3 & 2 & 6 & 2 & 1 & 2 & 7 & 2 & 8 & 4 & 3 & 1 & 2 & 5 \\
\hline 4 & 0 & 4 & 6 & 2 & 3 & 5 & 1 & 9 & 5 & 3 & 1 & 1 & 7 \\
\hline 5 & 3 & 4 & 3 & 0 & 4 & 6 & 2 & 8 & 4 & 3 & 1 & 1 & 6 \\
\hline Cohort & & & & & & & & & & & & & \\
\hline 1 & 9 & 9 & 7 & 3 & 6 & 16 & 9 & 16 & 11 & 1 & 4 & 3 & 9 \\
\hline 2 & 5 & 10 & 10 & 3 & 8 & 14 & 3 & 22 & 13 & 9 & 0 & 7 & 15 \\
\hline
\end{tabular}


Table 3: Aggregated Results for Problem 3

Matrix Version 3M

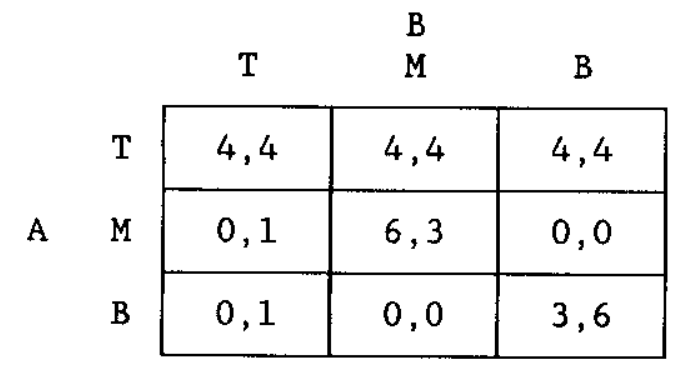

Sequential Version $3 \mathrm{~S}$

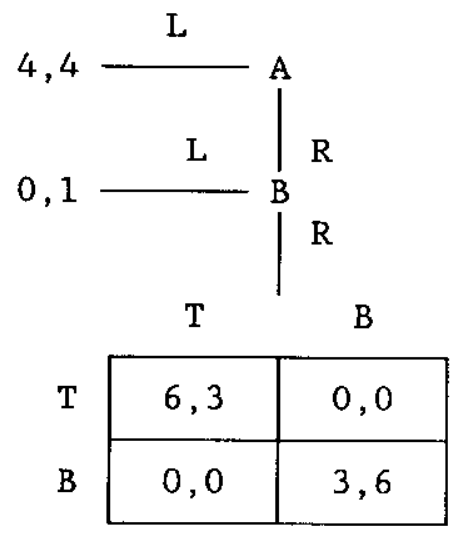

Number of Subjects Making Each Choice

Game:

Subject:

A

$3 M$

$3 S$

\begin{tabular}{|c|c|c|c|c|c|c|c|c|c|c|c|c|c|}
\hline Choices: & $\mathrm{T}$ & M & B & $\mathrm{T}$ & M & B & L & $\mathrm{R}$ & RT & $\mathrm{RB}$ & L & RT & $\mathrm{RB}$ \\
\hline Total & 41 & 8 & 1 & 35 & 13 & 2 & 35 & 15 & 13 & 0 & 2 & 4 & 9 \\
\hline \multicolumn{14}{|l|}{ Round } \\
\hline 1 & 9 & 1 & 0 & 8 & 2 & 0 & 4 & 6 & 4 & 0 & 2 & 2 & 2 \\
\hline 2 & 10 & 0 & 0 & 7 & 3 & 0 & 7 & 3 & 3 & 0 & 0 & 1 & 2 \\
\hline 3 & 6 & 3 & 1 & 6 & 3 & 1 & 8 & 2 & 2 & 0 & 0 & 1 & 1 \\
\hline 4 & 11 & 2 & 0 & 8 & 2 & 0 & 7 & 3 & 3 & 0 & 0 & 0 & 3 \\
\hline 5 & 8 & 2 & 0 & 8 & 2 & 0 & 9 & 1 & 1 & 0 & 0 & 0 & 1 \\
\hline \\
\hline 1 & 20 & 4 & 1 & 15 & 8 & 2 & 19 & 6 & 4 & 0 & 2 & 1 & 3 \\
\hline & 21 & 4 & 0 & 20 & 5 & 0 & 16 & 9 & 9 & 0 & 0 & 3 & 6 \\
\hline
\end{tabular}

A B

B

A 
Table 4: A Comparison of Individual subject Behavior

Number of Subjects Who Chose Each Strategy With a Given Frequency (Number of Rounds).

Problem 1M (Over the first 3 rounds)

Subject:

A

B

Choice:

Frequency

\begin{tabular}{|l|ll|rr}
0 & quency \\
1 & 6 & 8 & 12 & 1 \\
2 & 2 & 4 & 5 & 2 \\
4 & 2 & 2 & 5 \\
8 & 6 & 1 & 12 \\
\hline
\end{tabular}

Problem 2M (Over the first 5 rounds)

\begin{tabular}{|c|c|c|c|c|c|c|}
\hline Subject: & & A & & & B & \\
\hline Choice: & $\mathrm{T}$ & M & B & $\mathrm{T}$ & $M$ & B \\
\hline 0 & 2 & 0 & 0 & 4 & 3 & 0 \\
\hline 1 & 3 & 4 & 3 & 6 & 3 & 1 \\
\hline 2 & 4 & 3 & 7 & 0 & 1 & 3 \\
\hline 3 & 1 & 3 & 0 & 0 & 3 & 3 \\
\hline 4 & 0 & 0 & 0 & 0 & 3 & 1 \\
\hline 5 & 0 & 0 & 0 & 0 & 0 & 2 \\
\hline
\end{tabular}

\begin{tabular}{|c|c|c|c|c|c|c|}
\hline Subject: & & A & & & B & \\
\hline Choice: & $\mathrm{T}$ & $\mathbf{M}$ & B & $\mathrm{T}$ & M & B \\
\hline $\begin{array}{c}\text { Frequency } \\
0\end{array}$ & 0 & 4 & 9 & 2 & 6 & 8 \\
\hline 1 & 0 & 4 & 1 & 0 & 1 & 2 \\
\hline 2 & 0 & 2 & 0 & 1 & 1 & 0 \\
\hline 3 & 3 & 0 & 0 & 0 & 0 & 0 \\
\hline 4 & 4 & 0 & 0 & 2 & 0 & 0 \\
\hline 5 & 5 & 4 & 0 & 5 & 2 & 0 \\
\hline
\end{tabular}


Table 5: Results for Problem 1H

Represented as:

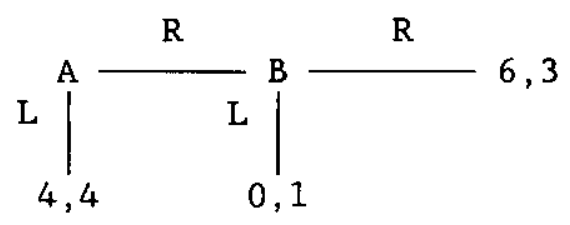

Played as :

\begin{tabular}{|c|c|c|}
\hline & \multicolumn{2}{|c|}{ B } \\
\hline & L & $\mathrm{R}$ \\
\hline L & 4,4 & 4,4 \\
\hline $\mathrm{R}$ & 0,1 & 6,3 \\
\hline
\end{tabular}

Number of Subjects Making Each Choice

Subject: $\quad$ A

\begin{tabular}{c|rr|rr|} 
Choice: & \multicolumn{1}{c}{$\mathrm{L}$} & $\mathrm{R}$ & $\mathrm{L}$ & $\mathrm{R}$ \\
\cline { 2 - 5 } Total & 11 & 66 & 10 & 67 \\
\cline { 2 - 5 } Round & & & & \\
\cline { 2 - 5 } 1 & 3 & 12 & 2 & 13 \\
2 & 1 & 14 & 3 & 12 \\
3 & 3 & 12 & 2 & 13 \\
4 & 2 & 13 & 2 & 13 \\
5 & 2 & 9 & 1 & 10 \\
6 & 0 & 6 & 0 & 6 \\
\hline & & & & \\
Cohort & 2 & 34 & 1 & 35 \\
1 & 8 & 17 & 2 & 23 \\
2 & 1 & 15 & 9 & 7 \\
3 & & &
\end{tabular}


Table 6: Results for Kodified Problem 3a

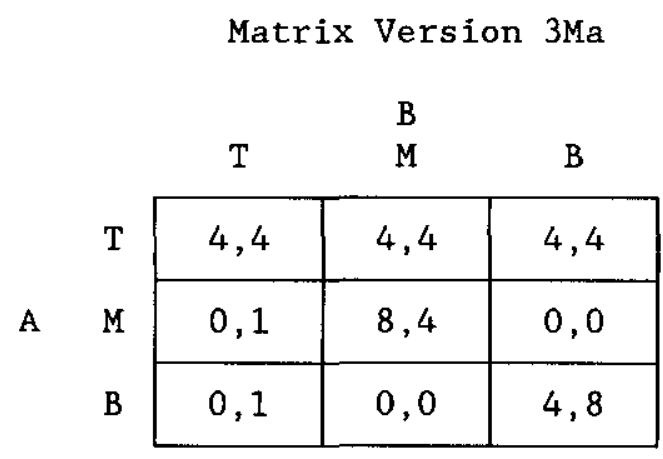

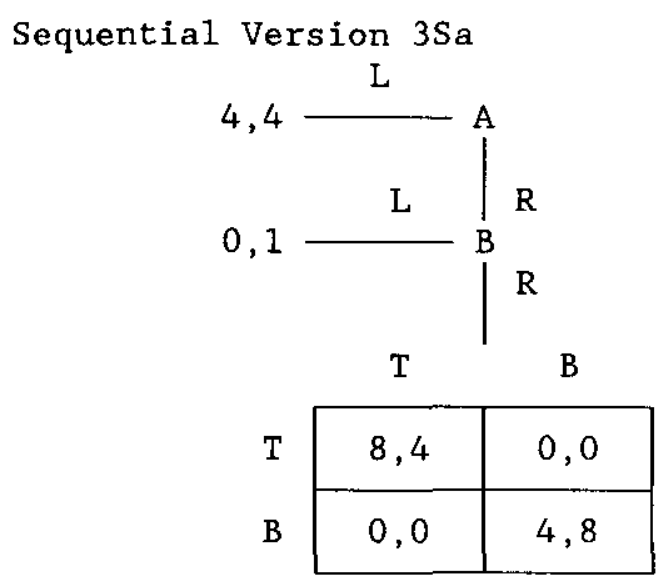

Number of Choices In Each Round

\begin{tabular}{|c|c|c|c|c|c|c|c|c|c|c|c|c|c|}
\hline \multirow{3}{*}{$\begin{array}{l}\text { Game: } \\
\text { Subject: } \\
\text { Choices: }\end{array}$} & \multicolumn{7}{|c|}{$3 \mathrm{Ma}$} & \multicolumn{6}{|c|}{$3 \mathrm{Sa}$} \\
\hline & \multicolumn{3}{|c|}{ A } & \multicolumn{3}{|c|}{ B } & \multicolumn{4}{|c|}{ A } & \multicolumn{3}{|c|}{ B } \\
\hline & $\mathrm{T}$ & M & B & $\mathrm{T}$ & M & B & L & $\mathrm{R}$ & RT & RB & $\mathrm{L}$ & $\mathrm{RT}$ & $\mathrm{RB}$ \\
\hline Total & 18 & 3 & 4 & 1 & 5 & 19 & 20 & 30 & 24 & 1 & 5 & 12 & 13 \\
\hline \multicolumn{14}{|l|}{ Round } \\
\hline 1 & 4 & 0 & 1 & 1 & 1 & 3 & 4 & 6 & 5 & 0 & 1 & 3 & 2 \\
\hline 2 & 3 & 2 & 0 & 0 & 0 & 5 & 4 & 6 & 4 & 1 & 1 & 2 & 3 \\
\hline 3 & 3 & 1 & 1 & 0 & 1 & 4 & 3 & 7 & 5 & 0 & 2 & 1 & 4 \\
\hline 4 & 4 & 0 & 1 & 0 & 1 & 4 & 5 & 5 & 5 & 0 & 0 & 3 & 2 \\
\hline 5 & 4 & 0 & 1 & 0 & 2 & 3 & 4 & 6 & 5 & 0 & 1 & 3 & 2 \\
\hline \multirow{3}{*}{$\begin{array}{c}\text { Cohort } \\
1 \\
2\end{array}$} & & & & & & & & & & & & & \\
\hline & 18 & 3 & 4 & 1 & 5 & 19 & 7 & 18 & 17 & 0 & 1 & 9 & 8 \\
\hline & & & & & & & 13 & 12 & 7 & 1 & 4 & 3 & 5 \\
\hline
\end{tabular}


Table 7: Results for Modified Problem 3b

Matrix Version $3 \mathrm{Mb}$

\begin{tabular}{|c|c|c|c|}
\hline & \multicolumn{3}{|c|}{ B } \\
\hline & $\mathrm{T}$ & $\mathbf{M}$ & B \\
\hline $\mathrm{T}$ & 4,4 & 4,4 & 4,4 \\
\hline M & 0,1 & 6,3 & 2,2 \\
\hline B & 0,1 & 2,2 & 3,6 \\
\hline
\end{tabular}

Sequential Version $35 b$

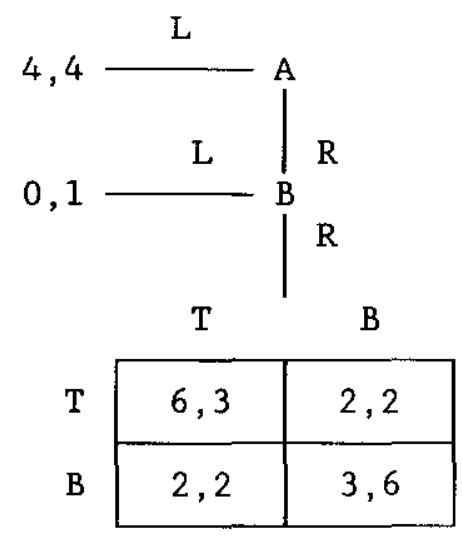

Number of Choices In Each Round

\begin{tabular}{|c|c|c|c|c|c|c|c|c|c|c|c|c|c|}
\hline \multirow{2}{*}{$\begin{array}{l}\text { Game: } \\
\text { Subject: }\end{array}$} & \multicolumn{6}{|c|}{$3 \mathrm{Mb}$} & \multicolumn{7}{|c|}{$3 s b$} \\
\hline & \multicolumn{3}{|c|}{ A } & \multicolumn{3}{|c|}{ B } & \multicolumn{4}{|c|}{ A } & \multicolumn{3}{|c|}{ B } \\
\hline Choices: & $\mathrm{T}$ & M & B & $\mathrm{T}$ & M & B & $\mathrm{L}$ & $\mathrm{R}$ & RT & $\mathrm{RB}$ & $\mathrm{L}$ & $\mathrm{RT}$ & $\mathrm{RB}$ \\
\hline Total & 44 & 24 & 4 & 8 & 23 & 41 & 27 & 45 & 37 & 2 & 6 & 12 & 27 \\
\hline \multicolumn{14}{|l|}{ Round } \\
\hline 1 & 11 & 1 & 0 & 1 & 4 & 7 & 3 & 9 & 8 & 0 & 1 & 2 & 6 \\
\hline 2 & 7 & 4 & 1 & 1 & 3 & 8 & 1 & 11 & 10 & 0 & 1 & 4 & 6 \\
\hline 3 & 7 & 5 & 0 & 2 & 4 & 6 & 7 & 5 & 5 & 0 & 0 & 2 & 3 \\
\hline 4 & 7 & 4 & 1 & 1 & 4 & 7 & 4 & 8 & 7 & 1 & 0 & 3 & 5 \\
\hline 5 & 9 & 2 & 1 & 2 & 4 & 6 & 7 & 5 & 4 & 0 & 1 & 0 & 4 \\
\hline 6 & 6 & 6 & 1 & 1 & 4 & 7 & 5 & 7 & 3 & 1 & 3 & 1 & 3 \\
\hline \multicolumn{14}{|l|}{ Cohort } \\
\hline 1 & 24 & 8 & 4 & 2 & 8 & 26 & 11 & 25 & 20 & 0 & 5 & 8 & 12 \\
\hline 2 & 20 & 16 & 0 & 6 & 15 & 15 & 16 & 20 & 17 & 2 & 1 & 4 & 15 \\
\hline
\end{tabular}


Table 8: Results for Repeated Version of Problem 3H

\begin{tabular}{|c|c|c|c|}
\hline & \multicolumn{3}{|c|}{ B } \\
\hline & $\mathrm{T}$ & M & B \\
\hline $\mathrm{T}$ & 4,4 & 4,4 & 4,4 \\
\hline M & 0,1 & 6,3 & 0,0 \\
\hline B & 0,1 & 0,0 & 3,6 \\
\hline
\end{tabular}

In sessions II, the roles of the subjects were reversed.

Number of Subjects Making Each Choice

Session:

I

Subject:

A

B

\begin{tabular}{c|ccc|ccc|}
\multirow{2}{*}{$\begin{array}{c}\text { Choices: } \\
\text { Tota1 }\end{array}$} & $\mathrm{T}$ & $\mathrm{M}$ & $\mathrm{B}$ & $\mathrm{T}$ & $\mathrm{M}$ & $\mathrm{B}$ \\
\cline { 2 - 7 } & 26 & 8 & 1 & 8 & 2 & 25 \\
\cline { 2 - 6 } Round & & & & & & \\
\cline { 2 - 7 } 1 & 4 & 2 & 0 & 1 & 1 & 4 \\
2 & 4 & 2 & 0 & 2 & 0 & 4 \\
3 & 5 & 0 & 1 & 2 & 0 & 4 \\
$4^{*}$ & 5 & 1 & 0 & 1 & 0 & 4 \\
5 & 3 & 3 & 0 & 1 & 1 & 4 \\
6 & 6 & 0 & 0 & 1 & 0 & 5 \\
\hline
\end{tabular}

II

A B

\begin{tabular}{|ccc|ccc|}
\multicolumn{1}{c|}{$\mathrm{T}$} & $\mathrm{M}$ & $\mathrm{B}$ & $\mathrm{T}$ & $\mathrm{M}$ & $\mathrm{B}$ \\
\hline 30 & 5 & 1 & 8 & 16 & 32 \\
\hline & & & & & \\
\hline 5 & 1 & 0 & 2 & 2 & 2 \\
5 & 0 & 1 & 2 & 3 & 1 \\
4 & 2 & 0 & 2 & 2 & 2 \\
6 & 0 & 0 & 2 & 2 & 2 \\
5 & 1 & 0 & 2 & 2 & 2 \\
5 & 1 & 0 & 2 & 2 & 2 \\
\hline
\end{tabular}

${ }^{*}$ In session $I$, one the pairs of responses in round 4 was not recorded.

Number of Subjects Who Chose Each Strategy With a Given Frequency.

Session:

Subject:

Choice:

Frequency

0
1
2
3
4
5
6

I

A

B

II

A $B$

\begin{tabular}{lll|lll|}
$\mathrm{T}$ & $\mathrm{M}$ & $\mathrm{B}$ & $\mathrm{T}$ & $\mathrm{M}$ & $\mathrm{B}$ \\
\hline 0 & 4 & 5 & 3 & 2 & 3 \\
0 & 0 & 1 & 1 & 2 & 1 \\
0 & 1 & 0 & 0 & 0 & 0 \\
2 & 1 & 0 & 0 & 0 & 0 \\
0 & 0 & 0 & 0 & 0 & 1 \\
0 & 0 & 0 & 2 & 0 & 0 \\
4 & 0 & 0 & 0 & 2 & 1 \\
\hline
\end{tabular}




\section{References}

Banks, Jeff, Colin F. Camerer, and David Porter, (1988) "Experimental Tests of Nash Refinements in Signalling Games," University of Rochester, May.

Banks, Jeffery S. and Joel Sobe1, (1987) "Equilibrium Selection in Signalling Games," Econometrica, 55, pp. 647-661.

Beard. T. Randa11 and Richard 0. Bell, Jr., (1990) "Do People Rely on the Utility Maximization of Others?: An Experimental Test", Auburn University, March.

Brandts, Jordi, and Charles A. Holt (1988), "An Experimental Test of Equilibrium Dominance in Signalling Games," University of Virginia Department of Economics Working Paper.

Camerer, Colin F, and Keith Weigelt (1988), "Experimental Tests of a Sequential Equilibrium Reputation Mode1," Econometrica, 56, pp. 1-36.

Cho, In-Koo, and David M. Kreps (1987), "Signalling Games and Stable Equilibria," Quarterly Journal of Economics, 102, pp. 179-221.

Cooper, Russe11, Douglas V. DeJong, Robert Forsythe, and Thomas W. Ross, (1989) "Communication in the Battle of the Sexes Game: Some Experimental Evidence," Rand Journal of Economics, Vol. 20, no. 4, Winter, pp. 568-587.

Cooper, Russe11, Douglas V. DeJong, Robert Forsythe, and Thomas W. Ross, (1990) "Selection Criteria in Coordination Games: Some Experimental Evidence," American Economic Review, Vol. 80, no. 1, March, pp. 218-233.

Kahneman, Daniel, Amos Tversky, (1979) "Prospect Theory: An Analysis of Decision Under Risk", Econometrica, Vo1. 47, No. 2 (March), pp. 263-292.

Kohlberg, Elon, Jean-Francois Mertens, (1986) "On the Strategic Stability of Equilibrium", Econometrica, Vo1. 54, No. 5 (September), pp. 1003-1037.

Kreps, David M., Robert Wilson, (1982) "Sequential Equilibrium", Econometrica, Vo1. 50, No. 4 (July), pp. 863-894.

Selten, Reinhardt, "Reexamination of the Perfectness Concept for Equilibrium Points in Extensive Games", (1975) International Journal of Game Theory, Vol. 4, No. 1 , pp. 25-55.

John B. Van Huyck, Ann B. Gillette, and Raymond C. Battaliio, (1989) "Credible Assignments in Coordination Games," Working Paper \#88-33, Texas A\&M University, June.

John B. Van Huyck, Raymond C. Battaliio, and Richard O. Beil, (1990) "Tacit Coordination Games, Strategic Uncertainty, and Coordination Failure", American Economic Review, Vo1 89, no. 1, March, pp 234-248. 


\section{Appendix}

This appendix contains the instructions for experiments $1 \mathrm{M}$ and $1 \mathrm{~S}$.

\section{A.1 Experiment $1 \mathrm{M}$}

Subject Type

\section{INSTRUCTIONS}

This is an experiment in decision making. Several research foundations have provided funds for these experiments. If you follow the instructions, and make good decisions, you may earn a sizable amount of money.

The experiment consists of two parts. The first part will be "practice", in the sense that payoffs will be non monetary letter payoffs. The second part of the experiment is where your dollar earnings will be determined. Here your decisions will earn you monetary payoffs which will be paid to you in cash.

\section{PRACTICE ROUNDS}

Half of the subjects in the room have been designated as type A subjects and half as type B subjects. Your type is printed in the upper right hand corner of this instruction sheet. Before each round you will be paired with a subject of the opposite type. The experiment will last for 6 rounds. Before each round the subject you are paired with will be randomly selected by the computer.

In each decision round, the two of you will simultaneously choose between two alternatives. The choices made by the two of you will determine how many points you earn in that round.

The payoffs resulting from the decisions that the two of you make in any round are described in the matrix below. That is, this matrix tells you the outcome of the four possible decision choice pairs. The two choices for subject B are listed along the top of the matrix. The two choices for Subject A are listed along the left side of the matrix. For any pair of choices, the first letter in the corresponding box gives you the payoff to Subject $A$, and the second letter gives the payoff to Subject B.

\begin{tabular}{lccc} 
& \multicolumn{2}{c}{ Choices for Subject B } \\
Choices for & L & M,$W$ & R \\
Subject A & R & A,B & Q, K \\
\end{tabular}

\section{Some Examples:}

Suppose Subject A selects Choice L and Subject B selects Choice R. Then the outcome is represented by the letters $\mathrm{Q}, \mathrm{K}$.

Suppose Subject A selects Choice $R$ and Subject B selects Choice L. Then the outcome is represented by the letters $A, B$. 
EXPERIMENTAL PROCEDURES

As you sit at your computer the monitor screen should look like this:

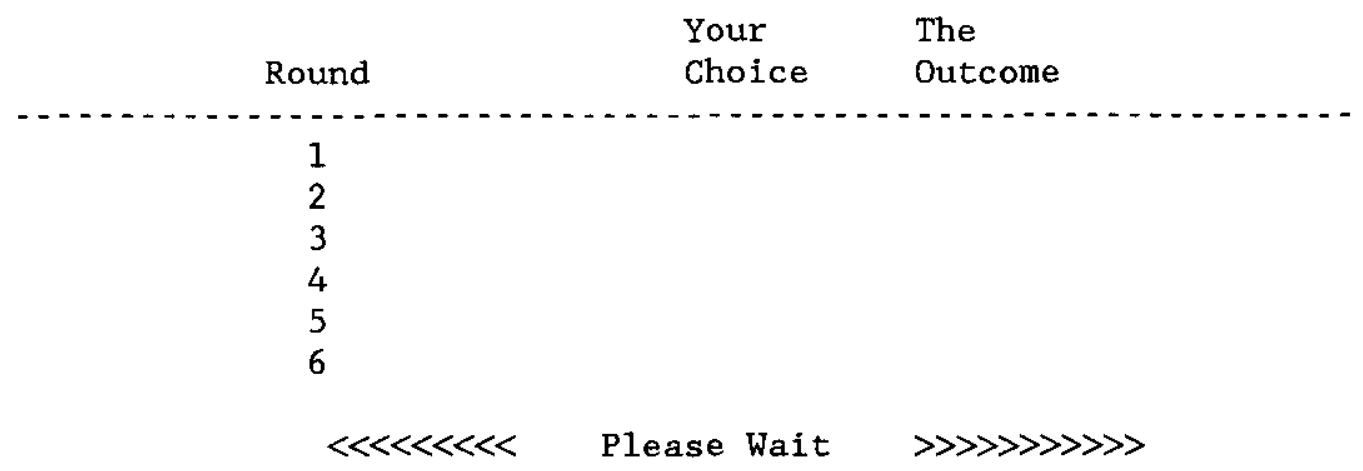

As the experiment proceeds you and your various counterparts will fill in the columns of this screen by making your choices. In round 1 when we tell you to begin, the following prompt will appear at the bottom of your screen:

Please make your choice: $\mathrm{L}$ or $\mathrm{R}$

You will then type the letter $\mathrm{L}$ or $\mathrm{R}$ into the keyboard. The computer will then respond with the following message at the bottom of the screen:

Is ___ your choice? (Y/N)

If this choice is the one you want, type $Y$. That will enter your choice into the computer. If you type $\mathrm{N}$, the computer will ask you to choose again.

Your counterpart for that round will be asked to do the same thing. After both of you have recorded your choices, the computer will compute your earnings and the following message will appear at the bottom of the screen:

You selected Choice _... The outcome is __. $<\quad$ Press any key to Continue $\quad>$

The computer will then record this information in the table above (on your monitor screen). You will then be asked to wait until all subjects in the experiment have completed the round. Notice that you are not explicitly told what choice your counterpart selected.

After completing round 1 you then proceed to round 2. We will proceed this way for 6 rounds. 
YOUR DECISION PROBLEM

This decision situation is very similar to the one you just completed. Half the subjects in the room have been designated as type A subjects and half as type B subjects. Your type is printed in the upper right hand corner of the instruction sheet. Before each round you will be paired with a subject of the opposite type. The experiment will last for 5 rounds. In each of the five rounds, you will play against a different subject of the opposite type. That is, you will never play against the same subject of the opposite type more than once.

As before, in each decision round the two of you will simultaneously choose between two alternatives. The choices by the two of you will determine how many points you earn in that round.

The payoffs resulting from the decisions that the two of you make in any round are described in the matrix below. That is, this matrix tells you how many points each of the four possible decision choice pairs are worth to you. The two choices for Subject $B$ are listed along the top of the matrix. The two choices for subject $A$ are listed along the left side of the matrix. For any pair of choices, the first number in the corresponding box gives you the point payoff to Subject $A$, and the second number gives the point payoff to Subject B.

\begin{tabular}{lccc} 
& \multicolumn{2}{c}{ Choices } & for Subject B \\
& & $\mathrm{L}$ & $\mathrm{R}$ \\
Choices for & L & 4,4 & 4,4 \\
Subject A & R & 0,1 & 6,3
\end{tabular}

\section{Some Examples:}

Suppose Subject A selects Choice $L$ and Subject B selects Choice $R$. Then Subject A earns 4 points and Subject B earns four points.

Suppose Subject A selects Choice $R$ and Subject B selects Choice L. Then Subject $A$ earns 0 points and Subject $B$ earns 1 point.

\section{PAYOFFS}

Your dollar earnings for the experiment are determined as follows. First, we will sum up your point total over the 5 rounds. Then we will multiply this sum by $\$ .70$.

The procedure will be the same one you followed in the practice game. Remember, in each round you will be paired with a new (and different) counterpart. You will never play against the same counterpart more than once. 


\section{INSTRUCTIONS}

This is an experiment in decision making. Several research foundations have provided funds for these experiments. If you follow the instructions, and make good decisions, you may earn a sizable amount of money. The experiment consists of two parts. The first part will be "practice", in the sense that payoffs will be non-monetary letter payoffs. The second part of the experiment is where your dollar earnings will be determined. Here your decisions will earn you monetary payoffs which will be paid to you in cash.

\section{PRACTICE ROUNDS}

Half of the subjects in the room have been designated as type A subjects and half as type $B$ subjects. Your type is printed in the upper right hand corner of this instruction sheet. Before each round you will be paired with a subject of the opposite type with this subject being randomly selected by the computer. The experiment will last for 6 rounds.

In each round, the decision problem faced by you and your counterpart is summarized in the diagram below. The choices made by the two of you will determine how many points you earn in the round. Subject A chooses first. If Subject $A$ selects $L$, then Subject $B$ has no choice and Subject $A$ receives $M$ and Subject $B$ receives $W$. If Subject $A$ chooses $R$, then Subject $B$ must make a choice. If Subject $B$ chooses $L$, then subject $A$ receives $A$ and Subject $B$ receives $B$. If Subject $B$ chooses $R$, then Subject $A$ receives $C$ and Subject $B$ receives $P$.

Payoff - Subject A

Payoff - Subject B

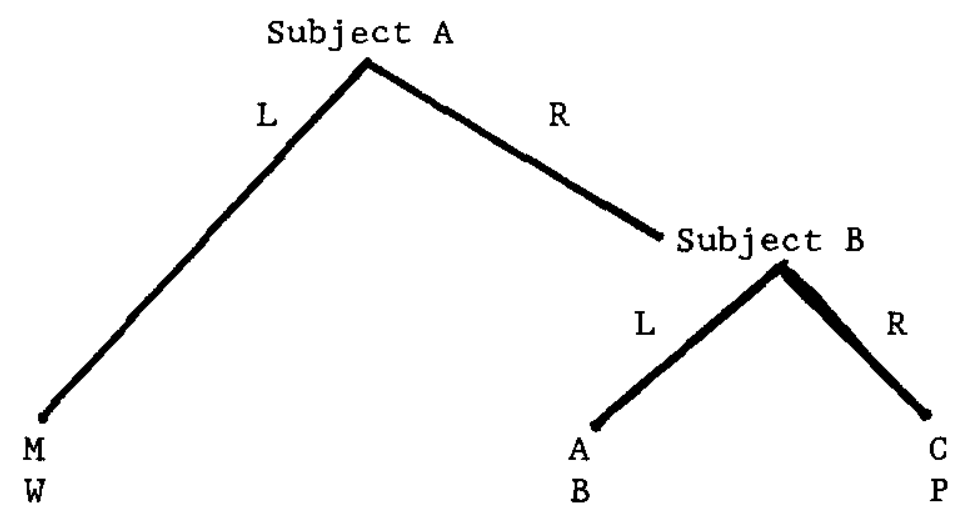

\section{Some Eramples:}

Suppose Subject A selects Choice $L$. Then the outcome is represented by the letters $\mathrm{M}, \mathrm{W}$.

Suppose Subject A selects Choice $R$ and Subject B selects Choice L. Then the outcome is represented by the letters A,B. 
EXPERIMENTAL PROCEDURES

As you sit at your computer the monitor screen should look like this:

Rou
1
2
3
4
5
6

Your The

Choice Outcome

1
2
3
4
5
6

$<<<<<<<<\quad$ Please Wait $\quad \gg \gg>>>>>>>$

As the experiment proceeds you and your various counterparts will fill in the columns of this screen by making your choices.

If you are Subject A:

In round 1 when we tell you to begin, the following prompt will appear at the bottom of your screen:

Please make your choice: $\mathrm{L}$ or $\mathrm{R}$

You will then type the letter $\mathrm{L}$ or $\mathrm{R}$ into the keyboard. The computer will then respond with the following message at the bottom of the screen:

Is __ your choice? (Y/N)

If this choice is the one you want, type $Y$. That will enter your choice into the computer. If you type $\mathrm{N}$, the computer will ask you to choose again.

If you select Choice $L$, then the following prompt will appear at the bottom of the screen:

You selected Choice $L$. The round is over. You earned $M$ $<$ Press any key to continue $>$

If you select choice $R$, the following prompt will appear at the bottom of the screen:

You selected Choice R.

$\ll \quad$ Please wait while Subject B makes his choice $>$

After Subject B makes his choice, the computer computes the payoffs and the following message appears at the bottom of the screen:

You selected Choice _. The outcome is $<\quad$ Press any key to Continue $\quad>$

The computer will then record this information in the table above (on your monitor screen). You will then be asked to wait until all subjects in the experiment have completed the round. Notice that you are not explicitly told what choice your counterpart selected. 
If you are subject B:

In round 1 when we tell you to begin, the following prompt will appear at the bottom of you screen:

$<\quad$ Please wait for Subject A to make a choice $>$

If Subject A chooses $\mathrm{L}$, the round is over and the following prompt will appear at the bottom of the screen:

$<$ You have no choice to make. You earned 4 points $>$ $<$ Press any key to continue $>>$

The computer will then record this information in the table above. An asterisk (*) will indicate you had no choice to make. You will then be asked to wait until all subjects have completed the round.

If Subject $A$ chooses $R$, the following prompt will appear.

Please make a choice: $\mathrm{L}$ or $\mathrm{R}$

You will then type the letter $\mathrm{L}$ or $\mathrm{R}$ into the keyboard. The computer will then respond with the following message at the bottom of the screen:

Is __ your choice? ( $\mathrm{Y} / \mathrm{N})$

If this choice is the one you want, type Y. That will enter your choice into the computer. If you type $\mathrm{N}$, the computer will ask you to choose again.

After you make your choice, the following prompt will appear at the bottom of the screen:

You selected Choice __. You earned __ points.

After completing round 1 you then proceed to round 2 . We will proceed this way for 6 rounds.

YOUR DECISION PROBLEM

This decision situation is very similar to the one you just completed. Half the subjects in the room have been designated as type $A$ subjects and half as type B subjects. Your type is printed in the upper right hand corner of the instruction sheet. Before each round you will be paired with a subject of the opposite type. The experiment will last for 4 to 6 rounds. In each round, you will play against a different subject of the opposite type. That is, you will never play against the same subject of the opposite type more than once.

As before, in each decision round the two of you will choose between two alternatives. The choices by the two of you will determine how many points you earn in that round.

The payoffs resulting from the decisions that the two of you make in any round are described in the diagram below. That is, this diagram tells you how many points each of the four possible decision choice pairs are worth to you. 


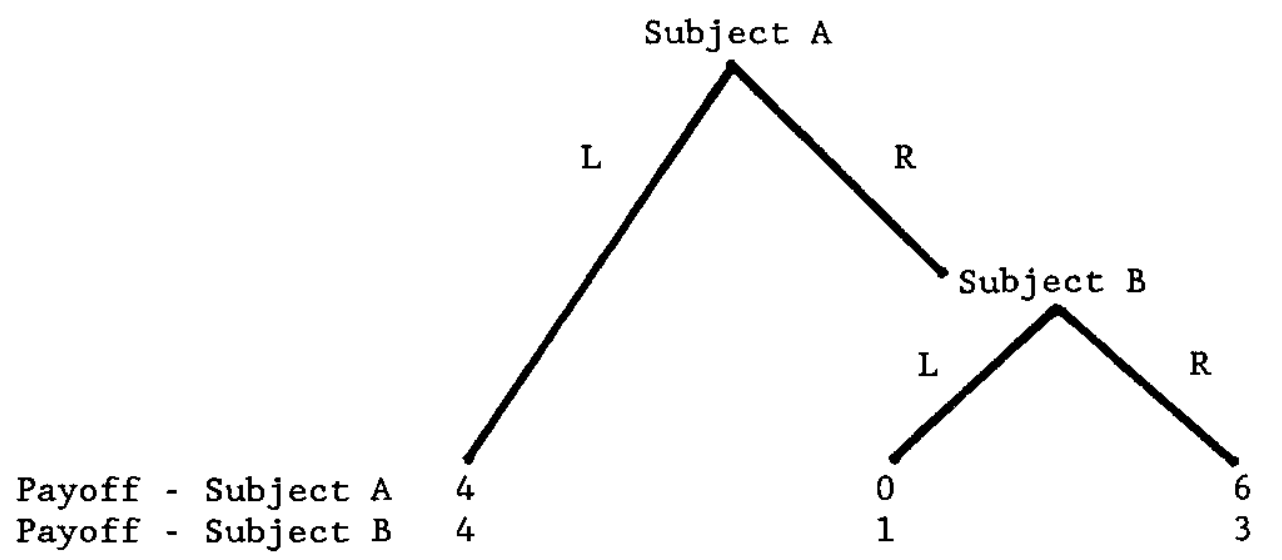

\section{Some Examples:}

Suppose Subject A selects Choice L. Then Subject A earns 4 points and Subject B earns four points.

Suppose Subject A selects Choice R and Subject B selects Choice L. Then Subject $A$ earns 0 points and Subject B earns 1 point.

\section{PAYOFFS}

Your dollar earnings for the experiment are determined as follows. First, we will sum up your point total over the 5 rounds. Then we will multiply this sum by $\$ .70$.

The procedure will be the same one you followed in the practice game. Remember, in each round you will be paired with a new (and different) counterpart. You will never play against the same counterpart more than once. 